\title{
Irreversible Processes During Martensitic Transformation in Zr-Based Shape Memory Alloys
}

\author{
G.S. Firstov, Yu.N. Koval and J. van Humbeeck* \\ Institute of Metal Physics of the National Academy of Sciences of Ukraine, 36 Vernadsky Str., \\ 252680 Kiev-142, Ukraine \\ * Katholieke Universiteit Leuven, de Croylaan 2, 3001 Leuven, Heverlee, Belgium
}

\begin{abstract}
The purpose of this paper is to explain the thermodynamical and shape memory behaviour in comparison with structural parameters for Zr-based intermetallics - a new class of potential shape memory alloys (SMA) for high-temperature applications [1]. Electrical resistivity, structural, shape memory and calorimetric measurements were carried out for the $\mathrm{Zr}_{2} \mathrm{CuNi}-\mathrm{Zr}_{2} \mathrm{CuCo}$ quasibinary cross-section. It was shown that the martensitic transformation (MT) of the high -temperature B2 phase resulted in the simultaneous formation of the two martensitic phases belonging to the $\mathrm{P} 2{ }_{1} / \mathrm{m}$ (B19' type) and $\mathrm{Cm}$ space groups in the case of $\mathrm{Zr}_{2} \mathrm{CuNi}$ similar to $\mathrm{ZrCu}$ [2]. Co for Ni substitution causes the changes in the martensite volume fractions up to formation of only B19' type martensite in $\mathrm{Zr}_{2} \mathrm{CuCo}$ compound without significant changes in lattice parameters for both martensites. Such substitution also decreases generally the transformation heats and energy dissipated during the full cycle of MT. The non-thermoelastic behaviour that was observed in [1] for $\mathrm{Zr}_{2} \mathrm{CuNi}$ changes to a thermoelastic one in the case of $\mathrm{MT}$ in $\mathrm{Zr}_{2} \mathrm{CuCo}$. Shape memory effect (SME) is nearly complete for alloys with high $\mathrm{Ni}$ content (not less than $85 \%$ of shape recovery ratio $\left(\mathrm{K}_{\mathrm{sme}}\right)$ ). It becomes complete at Co additions. The effect of the interaction between two martensites on the non-thermoelastic MT behaviour and SME in $\mathrm{Zr}$-based intermetallics is discussed in the present paper.
\end{abstract}

\section{INTRODUCTION}

It is known that the $\mathrm{Zr}$-based intermetallics undergo MT with wide temperature hysteresis. A considerable energy is dissipated during a full transformation cycle [1]. Nevertheless, the SME related to the MT in these alloys is nearly complete $(\cong 90-100 \%)$ [1] (see also references in [1]). It was found [1] that the $\mathrm{MT}$ in $\mathrm{Zr}_{2} \mathrm{CuNi}$ and $\mathrm{Zr}_{2} \mathrm{CoNi}$ is of non-thermoelastic type in spite of the MT macroscopic reversibility. Partial reverse MT cycling in these compounds produces a significant decrease of the subsequent forward partial MT temperatures. Thermoelastic MT was observed only for $\mathrm{Zr}_{2} \mathrm{CuCo}$ compound where the partial MT cycles are internal in respect to the full cycle [1]. All these unusual effects can be attributed to the simultaneous formation of two differently ordered martensitic phases having monoclinic symmetry [1,2]. The formation of only one B19' martensite takes place during the forward $\mathrm{MT}$ in $\mathrm{Zr}_{2} \mathrm{CuCo}$ [1]. So, the study of $\mathrm{MT}$ parameter changes along the $\mathrm{Zr}_{2} \mathrm{CuNi}$ $\mathrm{Zr}_{2} \mathrm{CuCo}$ quasibinary cross-section (from non-thermoelastic to thermoelastic MT) will help us in understanding the MT and SME mechanisms in Zr-based intermetallics - potential SMA for high-temperature applications.

\section{EXPERIMENTAL}

The $\mathrm{Zr}$-base alloys used in this investigation were arc-melted from iodide zirconium, electrolytic copper, nickel and cobalt in an argon atmosphere. Their good homogeneity was confirmed by X-ray microanalysis (JCXA733). The hysteresis loops and MT temperatures were determined by ac electrical resistivity measurements. SME was examined by a bending technique [3]. MT heats were detected by TA 2920 and Netzcsh 404 differential scanning calorimeters in the $170 \mathrm{~K} \leftrightarrow 800 \mathrm{~K}$ and $300 \mathrm{~K} \leftrightarrow 1200 \mathrm{~K}$ temperature ranges respectively. Crystal structure analysis as performed using X-ray diffractometry (DRON-1.0, Co- $\mathrm{K}_{\alpha}$ ) and Rietveld refinement (DBWS 9006PC program - new version [4]). 


\section{RESULTS AND DISCUSSION}

The results of electrical resistivity measurements are shown in Fig. 1, 2, 5. It is seen that the MT in the $\mathrm{Zr}_{2} \mathrm{CuNi}$ compound takes place with a wide hysteresis $(180 \mathrm{~K})$ and MT intervals $(100 \mathrm{~K})$. Co for Ni substitution results in a linear decrease of MT temperatures by $\approx 600 \mathrm{~K}$ (Fig. 2) and general hysteresis decrease to $50 \mathrm{~K}$ for $\mathrm{Zr}_{2} \mathrm{CuCo}$ with a maximum at $15-20$ at.\% of Ni (Fig. 5). The $\mathrm{A}_{\mathrm{S}}$ temperature, higher than $\mathrm{M}_{\mathrm{S}}$ at high Ni content, becomes lower than $\mathrm{M}_{\mathrm{S}}$ on $\mathrm{Co}$ additions (Fig. 2). Partial cycling in $\mathrm{Zr}_{2} \mathrm{CuNi}$ reveals the behaviour reported previously [1]. After stabilization of the full hysteresis loop (20 thermal cycles) partial reverse MT's result in much lower $\mathrm{M}_{\mathrm{S}}, \mathrm{M}_{\mathrm{f}}$ temperatures on subsequent cooling (Fig. $1 \mathrm{f}$ ). When the reverse partial cycles became more complete the shape of the partial hysteresis loops came nearer to the original (complete) hysteresis loop. A new full cycle showed again the original shape of the hysteresis loop. Addition of 4.42 at. $\%$ of Co weakens the effect mentioned above with the simultaneous appearance of the effect of the reverse MT temperatures increase on partial cycling (Fig. 1e, thin dashed line - 1st partial cycle, thin solid lines - subsequent cycles). It is clearly seen from Fig. 1d that partial cycling results in disappearing of the forward MT lowering effect for the alloy with 9.6 at.\% Co. The starting partial reverse path (Fig $1 \mathrm{~d}$, thin dashed line) shows usual behaviour but the subsequent partial reverse paths are outside of the stabilized complete hysteresis loop. The same behaviour was observed for the alloys containing 14.8 (Fig. 1 c) and 19.9 (Fig. 1 b) at.\% of Co. It can also be seen (Fig. 1 b, c, d, e) that every subsequent partial path is outside of (higher in temperature than) the previous one. Moreover, after the finishing of partial cycling the subsequent first complete reverse path is much higher in temperature even compared to the previous partial paths (Fig. $1 \mathrm{~b}, \mathrm{c}, \mathrm{d}$, bold dashed line). A final complete cycle has the same shape as the original stabilized one (Fig. $1 \mathrm{~b}, \mathrm{c}, \mathrm{d}$, e) similar to $\mathrm{Zr}_{2} \mathrm{CuNi}$ (Fig. $1 \mathrm{f}$ ). In the case of $\mathrm{Zr}_{2} \mathrm{CuCo}$ all partial cycles are internal in respect to the complete cycle (Fig. 1a) as it can be seen for the thermoelastic MT (see [5] for example).

$\mathrm{X}$-ray diffraction measurements confirm the presence of only one $\mathrm{B} 19^{\prime}$ type martensite in $\mathrm{Zr}_{2} \mathrm{CuCo}$ and simultaneous formation of two martensitic phases in $\mathrm{Zr}_{2} \mathrm{CuNi}$ belonging to the $\mathrm{P} 2_{1} / \mathrm{m}$ (B19' type) and $\mathrm{Cm}$ space groups similar to $\mathrm{ZrCu}$ [2]. The lattice parameters are not changed significantly along the $\mathrm{Zr}_{2} \mathrm{CuCo}-\mathrm{Zr}_{2} \mathrm{CuNi}$ cross-section because the atomic radii of $\mathrm{Co}$ and $\mathrm{Ni}$ are nearly identical. Considerable changes can be seen for $\mathrm{Cm}$ and $\mathrm{P} 2_{1} / \mathrm{m}$ martensite volume fractions (Fig.3) that were obtained according to [6]. The amount of the B19' type martensite volume fraction increases from $\approx 15 \%$ in $\mathrm{Zr}_{2} \mathrm{CuNi}$ to $\approx 95 \%$ in the alloy with 9.6 at.\% of $\mathrm{Co}$. The exact structural parameters for the studied cross-section will be published elsewhere [7].

SME for the $\mathrm{Zr}_{2} \mathrm{CuNi}-\mathrm{Zr}_{2} \mathrm{CuCo}$ quasibinary cross-section was studied under the $120 \mathrm{MPa}$ static load applied before cooling below the $\mathrm{M}_{\mathrm{S}}$ temperature. Then the specimens were released at $77 \mathrm{~K}$ after storing of $0.2-0.5 \%$ martensitic deformation for subsequent free shape recovery on heating. The composition dependence of the shape recovery ratio $\mathrm{K}_{\mathrm{SME}}=\left(\varepsilon_{\mathrm{M}} / \varepsilon_{\mathrm{R}}\right) \mathbf{1 0 0 \%}$ is shown in Fig. 4. It can be seen that the shape recovery becomes complete on Co additions through a minimum at $15-20$ at. \% of $\mathrm{Ni}\left(\mathrm{K}_{\mathrm{SME}} \geq 85 \%\right)$.

The results of calorimetric measurements are shown in Fig. 6-9. Considerable values of MT heats for the alloys with high $\mathrm{Ni}$ content (Fig. 6) are noticed. Co additions significantly decrease the transformation heats by $\approx 2$ $\mathrm{kJ} / \mathrm{mol}$. The difference in the reverse and forward MT heats that represents the energy lost in the complete MT

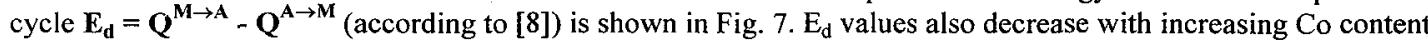
through the maximum at $\approx 20$ at.\% of $\mathrm{Ni}$ and correlate well with the thermal MT hysteresis behaviour (Fig. 5) and the minimum in shape recovery (Fig. 4). Exo- and endothermic reaction peaks during MT along $\mathrm{Zr}_{2} \mathrm{CuCo}$ $\mathrm{Zr}_{2} \mathrm{CuNi}$ quasibinary cross-section are shown in Fig. 8 and 9 respectively. Prolonged forward MT intervals for the alloys with higher Ni content are clearly divided into two overlapped stages (Fig. 8) as well as the reverse MT's (Fig. 9). The difference exists only in the actual temperature positions of the major and minor peaks. $\mathrm{In}_{2} \mathrm{r}_{2} \mathrm{CuNi}$ and alloys with 20.31 and 15.51 at.\% of $\mathrm{Ni}$ the second minor stage of the forward $\mathrm{MT}$ is lower in temperature than for the major stage (Fig. 8) in contrast with the reverse MT when the temperature position of the minor peak is higher (Fig. 9). The situation is changed drastically for the case of MT in the alloy containing $10.22 \mathrm{at} \% \mathrm{Ni}$. The minor stage of the reverse MT appears at temperatures lower than the major stage (Fig. 9) similar to the forward MT (Fig. 8). Further Co additions result in one stage behaviour for forward and reverse MT's.

Such correspondence between the different stages of forward and reverse MT's gives an opportunity to conclude that the MT in alloys with high Ni content is non-thermoelastic. The thermoelasticity concept that was confirmed experimentally [9] includes such requirement that the last portions of martensite phase on forward MT must be transformed to austenite in a first order. The minor peaks observed due to the formation of two different 
interacting martensite phases are lower in temperature than the major peaks (Fig. 8) and consequently they must be also lower than the major peaks on the reverse MT in the thermoelastic case. In reality, we have the opposite situation as was mentioned above (Fig. 9). Thus, a very high level of dissipative processes in a latter case can be influenced only by the elastic interaction between martensitic crystals of different type. Internal stresses produced by the major kind of martensitic crystals suppress the reverse MT for another kind of martensite. This explanation is valid for the case of $\mathrm{Cm}$ phase majority in $\mathrm{Zr}_{2} \mathrm{CuNi}$ where the major forward $\mathrm{MT}$ is prolonged as for an alloy with 15.51 at.\% Ni with the major B19' type phase having the sharp forward MT exothermic peak (Fig. 8). Only at 14.8 at.\% Co the situation becomes very close to the thermoelastic case. This can be concluded based on the observed sequence of the major and minor MT stages (last portions of martensite (minor kind) are transformed first into austenite).

The value of the internal shear stresses that can decrease the partial forward MT by $100 \mathrm{~K}$ can be estimated (Fig. 1 f, upper partial path). The Clausius - Clapeyron like equation can be rewritten as follows: $\mathbf{d} \tau=\frac{\mathbf{d T d Q}}{\mathbf{T}_{0} \mathbf{V}_{\text {mol }} \gamma}$, where $\mathbf{d} \tau$ - internal shear stress change associated with the martensite crystals, $\mathbf{d T}=100 \mathrm{~K}$ - partial forward MT temperature change, $\mathbf{d Q}=\mathbf{M} \mathbf{Q}^{\mathbf{A} \rightarrow \mathbf{M}}=0.2 \times 2320 \mathrm{~J} / \mathrm{mol}=464 \mathrm{~J} / \mathrm{mol}(\mathbf{M}$ - volume fraction of the martensite that will be formed on partial forward $M T ; \mathbf{Q}^{A \rightarrow M}$ - transformation heat of the complete forward MT), $\mathbf{T}_{\mathbf{0}} \approx 925 \mathrm{~K}$ - phase equilibrium temperature, $\mathbf{V}_{\text {mol }}=10.25 \times 10^{-6} \mathrm{~m}^{3} / \mathrm{mol}$ - molar volume of $\mathrm{Zr}_{2} \mathrm{CuNi}$ and $\gamma=0.1 \times(\mathrm{a} / \mathrm{b})=0.01$ - shear strain $(\mathrm{a} / \mathrm{b}$ - martensite crystals aspect ratio) and, finally, $\mathbf{d} \tau=0.489 \mathrm{GPa}$. Then, the shear stresses that can be produced by martensitic crystal in surrounding austenite can be estimated from the following expression: $\tau=\mathbf{G} \gamma=0.5 \mathbf{E} \gamma$, where $\mathbf{G}$ and $\mathbf{E}=265.7 \mathrm{GPa}$ [10] - shear and Young's moduli and we achieve $\tau=$ $1.328 \mathrm{GPa}$. So, it means that after partial reverse cycle small austenitic "islands" are imposed by elastic stresses produced by the neighbouring martensitic crystals and their influence is enough to suppress the subsequent forward partial MT in a way that we have observed (Fig.1 f). Naturally, the martensite crystals produce short range stresses in a matrix. That is why the maximal effect of partial forward MT decrease was achieved at smaller degrees of partial reverse MT. The shape of partial hysteresis loop came nearer to the shape of complete cycle at higher degrees of partial reverse MT because the austenite becomes more free from the influence of internal stresses. Thus, it can be concluded that the unusual behaviour on partial thermal cycling in $\mathrm{Zr}_{2} \mathrm{CuNi}$ compound may be attributed to the elastic interaction between martensitic crystals of different type and austenite due to the observed effect of the restoration of the original shape of the complete hysteresis loop after partial cycles.

Disappearence of the effect described above on Co additions is combined with the reverse partial paths of temperature increase that can be attributed to the significant changes in martensites volume fractions (Fig.3).

It should be fairly noted that all the estimations can be applied even for the thermoelastic $\mathrm{MT}$ in $\mathrm{Zr}_{2} \mathrm{CuCo}$ or in another known SMA where such effects are absent or very weak. It means that one has"to take into account not only the volume fractions of two different martensites but also their configurations in respect to each other. This task needs quantitative metallographic measurements that are now in progress.

\section{Acknowledgments}

G.S. Firstov and Yu.N. Koval acknowledge INTAS 931202 ext. project and the Ministry of Science and Technology of Ukraine. J. Van Humbeeck acknowledges the NFWO (National Foundation for Scientific Research).

\section{References}

[1] Yu.N. Koval, G.S. Firstov, J. Van Humbeeck, L. Delaey, W.Y. Jang, "B2 intermetallic compounds of Zr. New class of the shape memory alloys", Proc. of the ICOMAT-95, Lausanne 20-25 August 1995, Switzerland, R.Gotthardt and J. Van Humbeeck Eds., J. Physique IV, C8, 5, (Les Editions de Physique, 1995) pp. 1103-1108.

[2] D. Schryvers, G.S. Firstov, J.W. Seo, J. Van Humbeeck, Yu.N. Koval, Scripta Mat.,36, (1997) pp.11 19-1125.

[3] V.V. Martynov, L.G. Khandros, Fiz.Met. and Metall.,39, No.5, (1975) pp. 1037-1042.

[4] D.B. Wiles, R.A. Young, J. Appl. Cryst.,14, (1981) pp. 149-151.

[5] A. Cornelis, C.M. Wayman, Scripta Met., 10, (1976) pp. 359-364.

[6] R.J. Hill, C.J. Howard, J. Appl. Cryst., 20, (1987) pp. 467-481.

[7] G.S. Firstov, Yu.N. Koval, J. Van Humbeeck, to be published.

[8] J. Ortin, A. Planes, Acta Metall., 36, No.8, (1988) pp. 1873-1889.

[9] G.V. Kurdjumov, L.G. Khandros, Doklady Akad. Nauk SSSR, 66, (1949) pp. 211-221.

[10] G.S. Firstov, Yu.N. Koval, J. Van Humbeeck, unpublished results. 


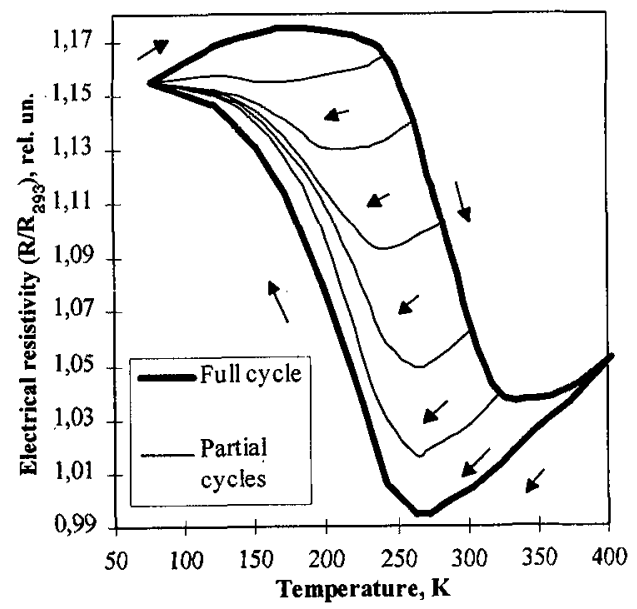

(a) $\mathrm{Zr}_{2} \mathrm{CuCo} \Rightarrow$

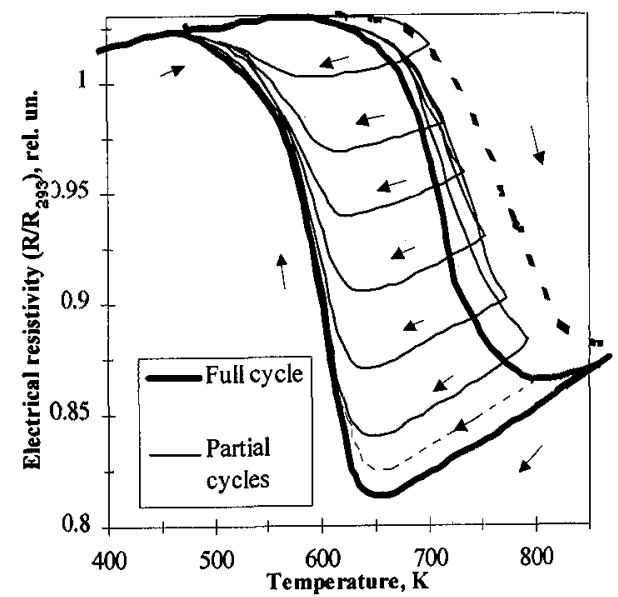

$\Rightarrow$ (d) $(9.6$ at. $\% \mathrm{Co}+15.51$ at.\%Ni) $\Rightarrow$

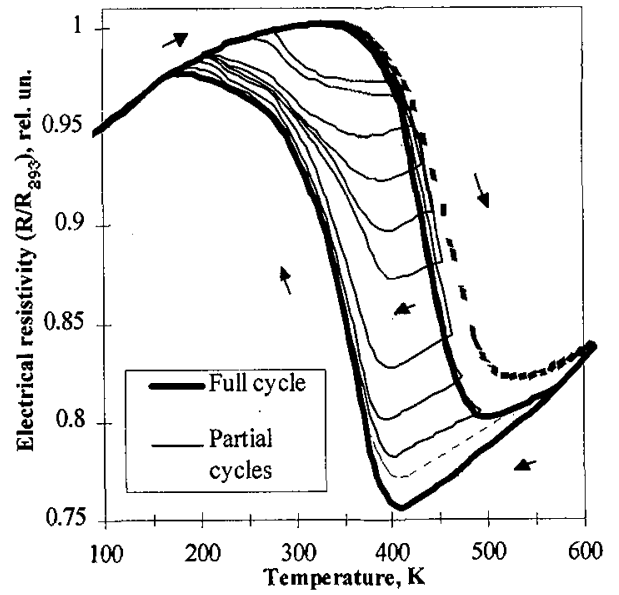

$\Rightarrow$ (b) $(19.9$ at. $\% \operatorname{Co}+4.4$ at. $\% \mathrm{Ni}) \Rightarrow$

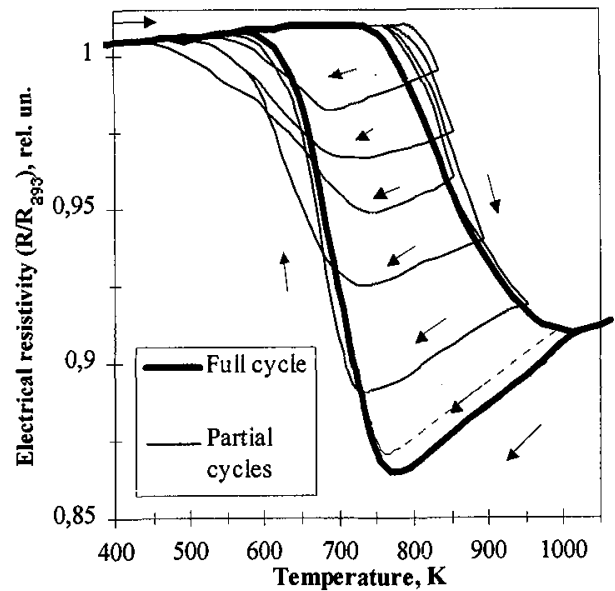

$\Rightarrow$ (e) (4.42 at.\%Co+20.31 at.\%Ni) $\Rightarrow$

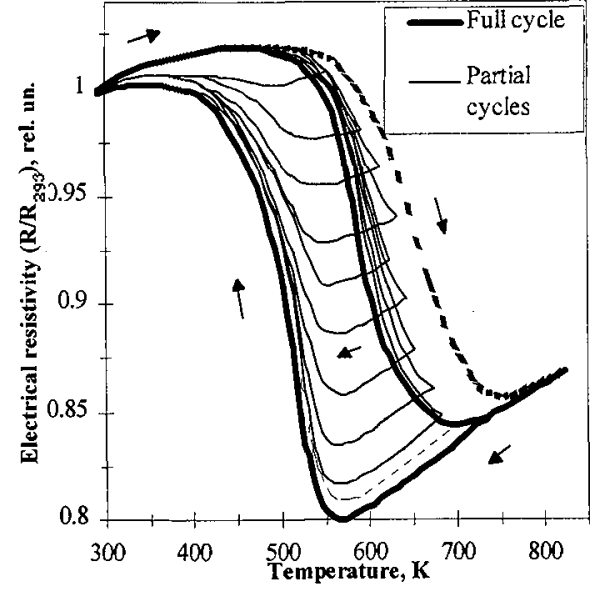

$\Rightarrow(\mathrm{c})(14.8$ at. $\% \mathrm{Co}+10.22$ at. $\% \mathrm{Ni}) \Rightarrow$

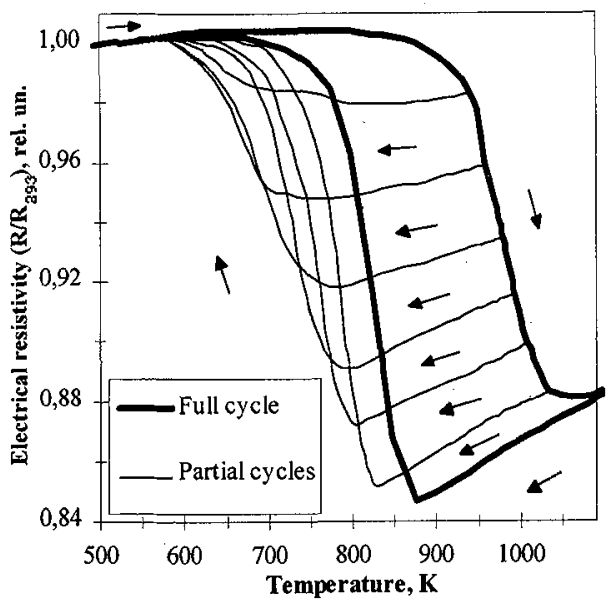

$\Rightarrow$ (f) $\mathrm{Zr}_{2} \mathrm{CuNi}$

Figure 1: Evolution of the MT hysteresis loops during full and partial thermal cycling along the $\mathrm{Zr}_{2} \mathrm{CuCo}-\mathrm{Zr}_{2} \mathrm{CuNi}$ quasibinary cross-section (Ni for Co substitution) 


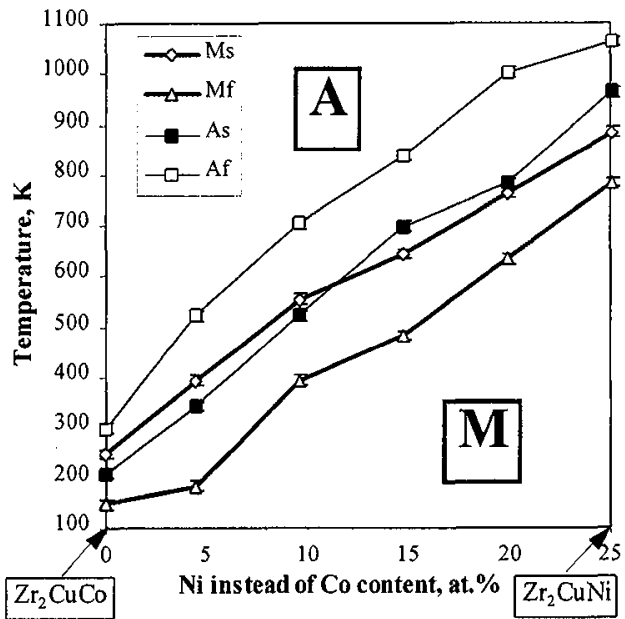

Figure 2: MT temperatures as a function of $\mathrm{Ni}$ content for the $\mathrm{Zr}_{2} \mathrm{CuNi}-\mathrm{Zr}_{2} \mathrm{CuCo}$ quasibinary cross-section

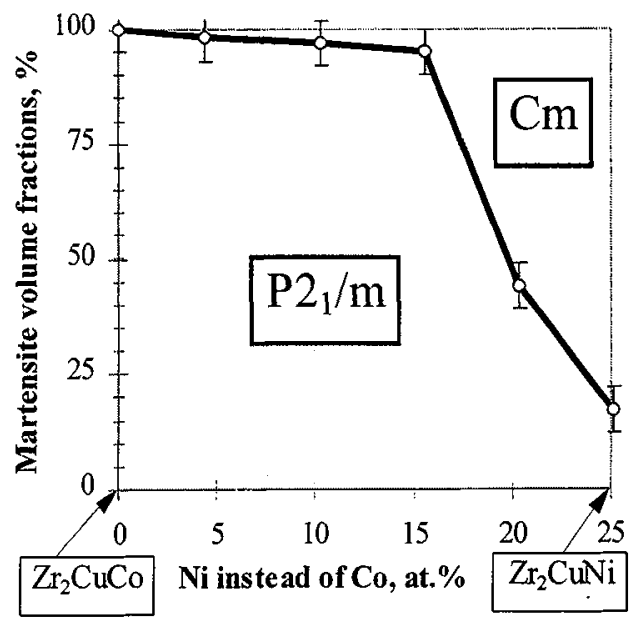

Figure 3: $\mathrm{Cm}$ and $\mathrm{P} 2 / \mathrm{m}$ martensite volume fraction changes vs $\mathrm{Ni}$ for Co substitution

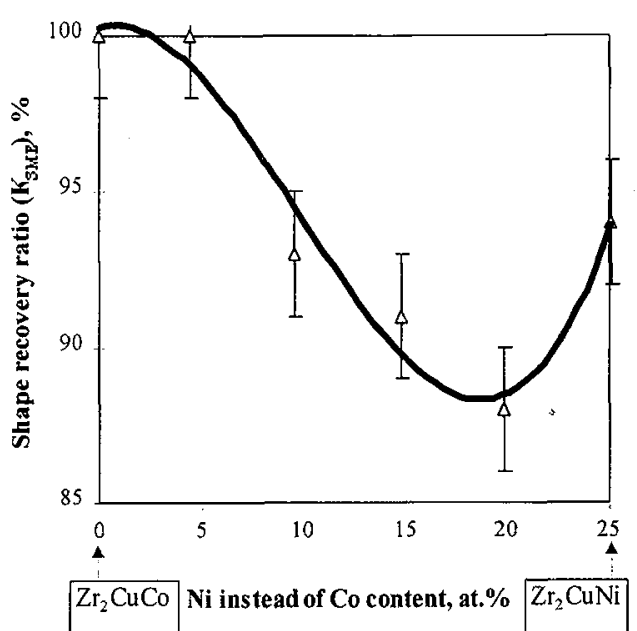

Figure 4: Shape recovery ratio vs $\mathrm{Ni}$ for $\mathrm{Co}$ substitution for the $\mathrm{Zr}_{2} \mathrm{CuCo}-\mathrm{Zr}_{2} \mathrm{CuNi}$ quasibinary cross-section

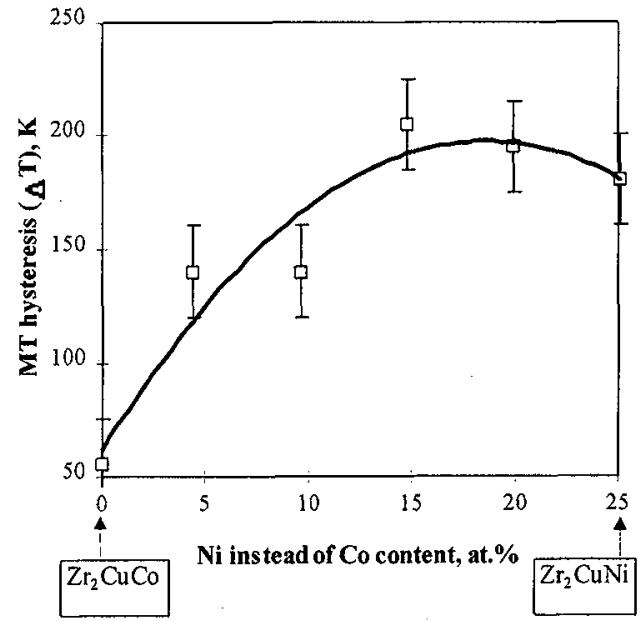

Figure 5: MT hysteresis changes vs $\mathrm{Ni}$ for Co substitution for the $\mathrm{Zr}_{2} \mathrm{CuCo}-\mathrm{Zr}_{2} \mathrm{CuNi}$ quasibinary cross-section

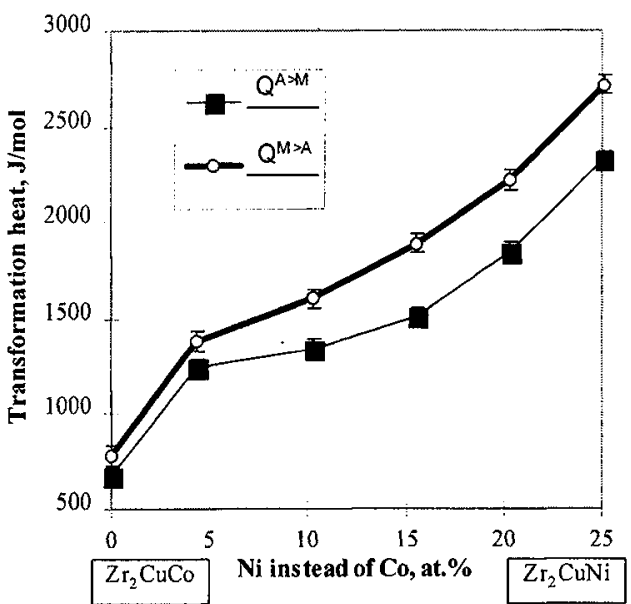

Figure 6: Martensite transformation heats as a function of $\mathrm{Ni}$ content for the $\mathrm{Zr}_{2} \mathrm{CuNi}-\mathrm{Zr}_{2} \mathrm{CuCo}$ cross-section

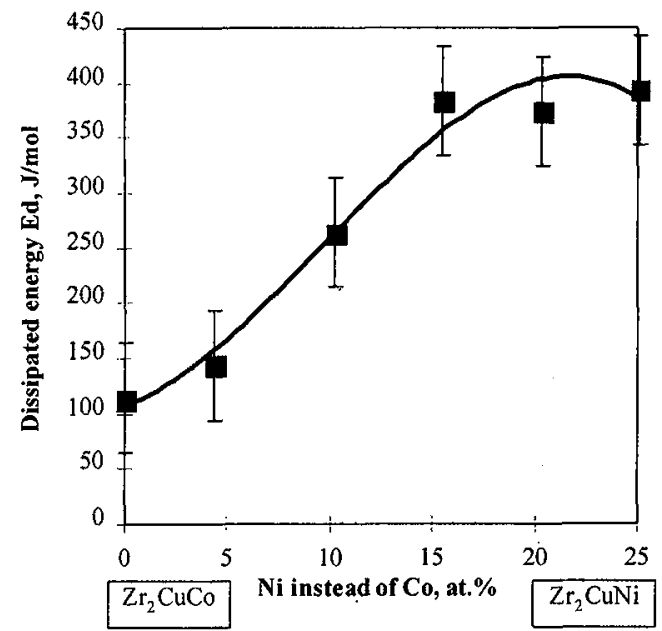

Figure 7: The energy dissipated on MT complete cycle $\left(E_{d}=Q^{M \rightarrow A}-Q^{A \rightarrow M}\right)$ vs Ni for Co substitution 


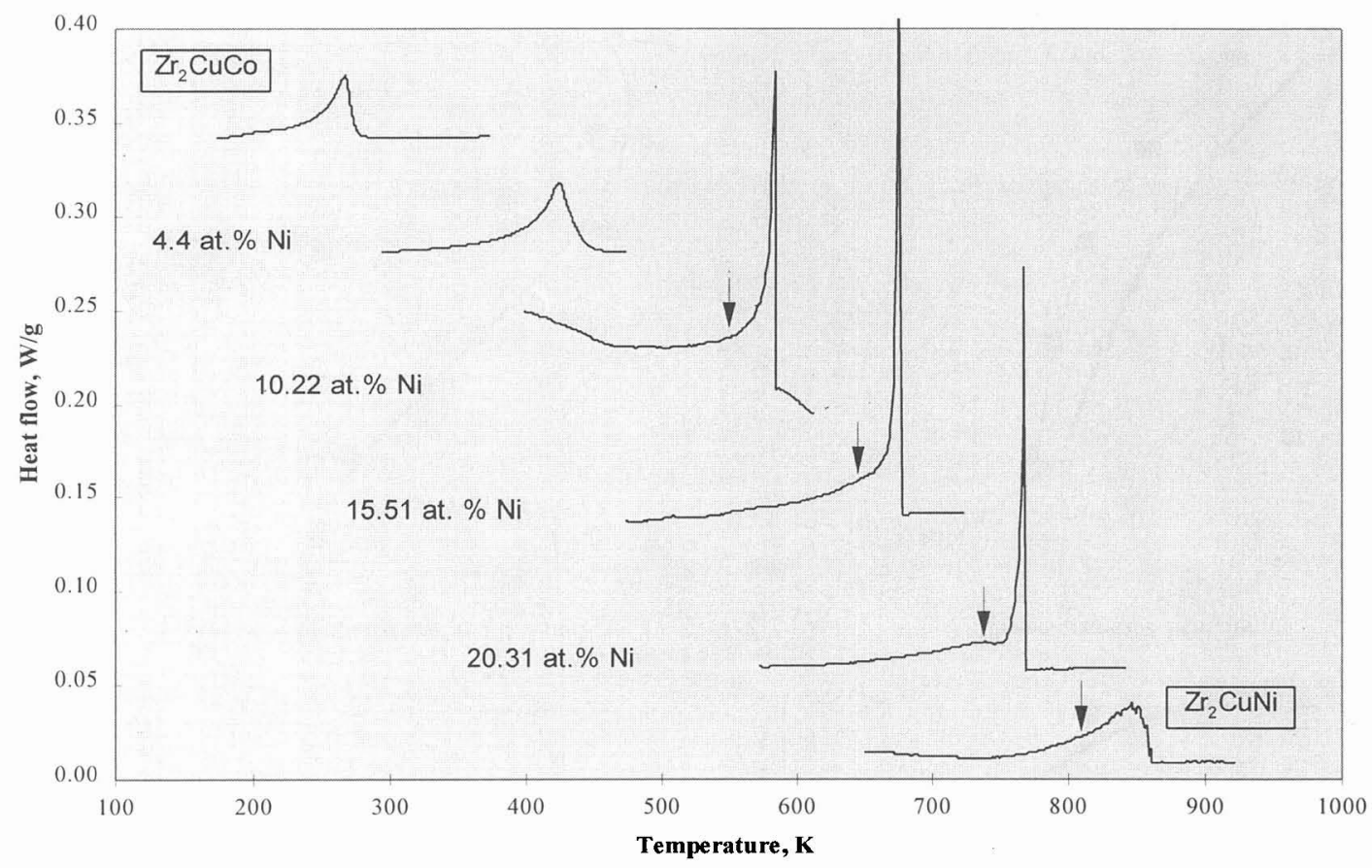

Figure 8: Evolution of exothermic reaction peaks during forward $\mathrm{MT}$ along the $\mathrm{Zr}_{2} \mathrm{CuCo}-\mathrm{Zr}_{2} \mathrm{CuNi}$ quasibinary cross-section (Ni for Co substitution); arrows indicate the position of the second stage of the forward MT.

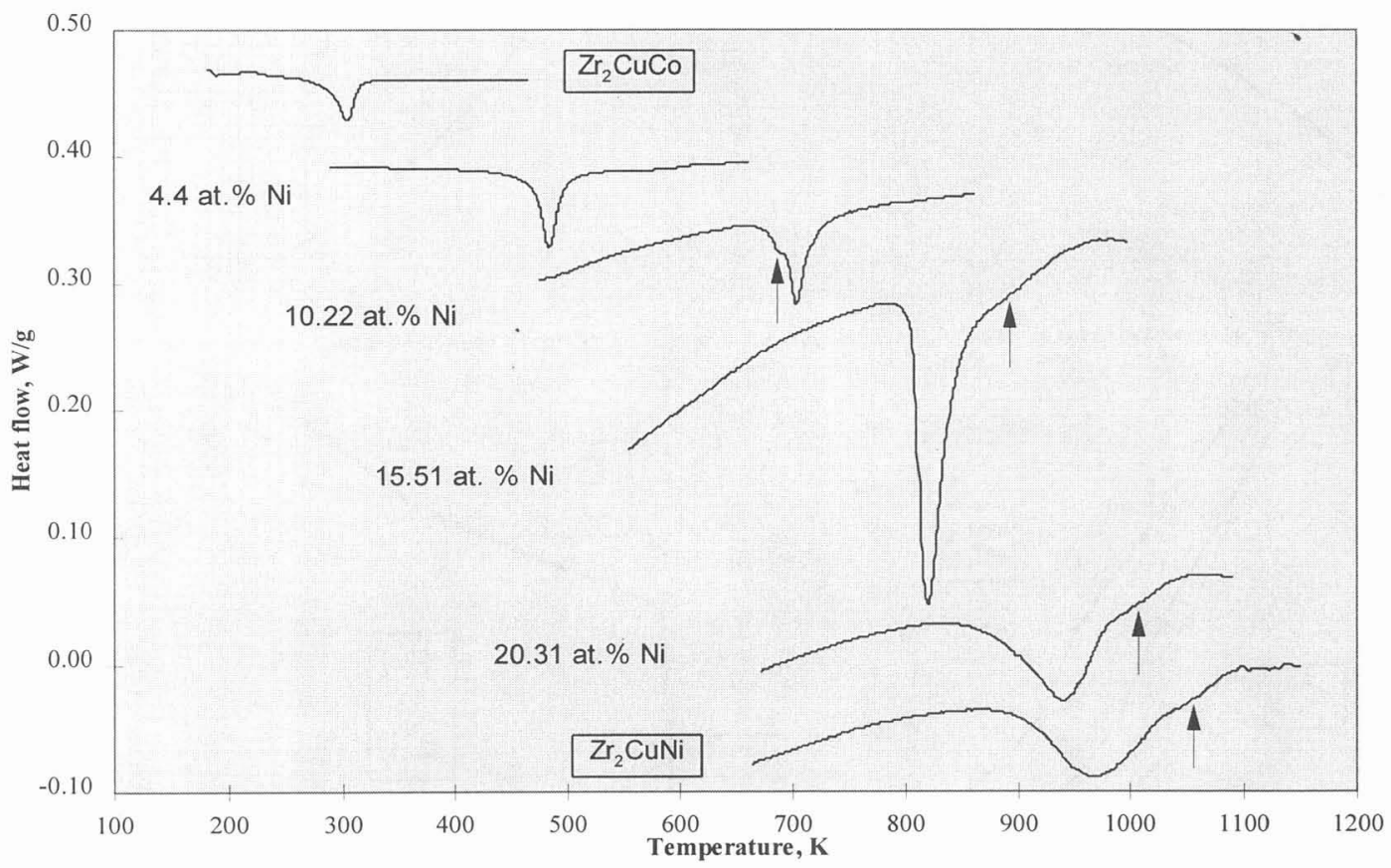

Figure 9: Evolution of endothermic reaction peaks during reverse $\mathrm{MT}$ along the $\mathrm{Zr}_{2} \mathrm{CuCo}-\mathrm{Zr}_{2} \mathrm{CuNi}$ quasibinary cross-section (Ni for Co substitution); arrows indicate the position of the reverse MT stage that can be puted into the correspondence with the second stage of the forward MT. 